\title{
Two Level Logistic Regression Model of Factors Influencing in Early Childbearing and its Consequences on Nutritional Status of Bangladeshi Mothers: Nationally Representative Data
}

\author{
Khirujjaman Sumon ${ }^{1}$, Md. Abu Sayem², Abu Sayed Md. Al Mamun², Premananda Bharati ${ }^{3}$, \\ Suman Chakrabarty ${ }^{4}$, Md. Abu Taleb ${ }^{5}$, Md. Sabiruzzaman ${ }^{1}$ and Md. Golam Hossain ${ }^{1, *}$ \\ ${ }^{1}$ Health Research Group, Department of Statistics, University of Rajshahi, Rajshahi-6205, Bangladesh \\ ${ }^{2}$ Former Nutrition Consultant, Unicef Bangladesh, Chapai Nawabganj, Bangladesh \\ ${ }^{3}$ Retired Professor \& Head, Biological Anthropology Unit, Indian Statistical Institute, 203 B.T. Road, Kolkata- \\ 700 108, India
}

${ }^{4}$ Department of Anthropology \& Coordinator of Department of Food and Nutrition, Mrinalini Datta Mahavidyapith, Birati, Kolkata - 700 051, West Bengal, India

${ }^{5}$ Senior Technical Advisor -TB, USAID Medicines, Technologies and Pharmaceutical Services (MTaPS) Program, Management Sciences for Health, Gulshan-1, Dhaka-1212, Bangladesh

\begin{abstract}
Background: Early marriage and early pregnancy is a social as well as a medical problem in developing countries, which may have an impact on the health and nutritional status of teenage mothers. Therefore, the objective of this study was to determine the influencing factors of early childbearing (ECB) and its consequences on the nutritional status of Bangladeshi mothers.

Methods: Data was extracted from Bangladesh Demographic and Health Survey (BDHS-2014). Women who delivered their first baby before the age of 20 years are considered ECB mothers. Nutritional status was measured by body mass index (BMI). Chi-square test and both univariable and multivariable logistic regressions, and z-proportional test were used in this study.

Results: The prevalence of ECB among currently non-pregnant mothers in Bangladesh was $83 \%$. The logistic regression model provided the following six risk factors of ECB: (i) living location (division) $(p<0.01)$, (ii) respondents' education $(p<0.05)$, (iii) husbands' education $(p<0.05)$, (iv) household wealth quintiles $(p<0.01)$, (v) respondents' age at first marriage $(p<0.05)$, and (vi) number of family members $(p<0.05)$. Still, $17.6 \%$ of mothers were undernourished in Bangladesh; among them, $18.5 \%$ and $13.4 \%$ were ECB and non- ECB mothers respectively. ECB mothers had a greater risk to be undernourished than non-ECB mothers [COR=1.26, 95\% $\mathrm{Cl}: 1.11-1.43 ; p<0.01]$.

Conclusions: In this study, some modifiable factors were found as predictors of ECB in Bangladesh. ECB mothers were more prone to become under-nourished. These findings can be considered to reduce the number of ECB mothers in Bangladesh consequently improve their nutritional status.
\end{abstract}

Keywords: Early childbearing mothers, Nutritional status, Socio-demographic factors, Two-level logistic regression model, Bangladesh.

\section{BACKGROUND}

The women who delivered children before age 20 years old are usually called early childbearing (ECB) mothers [1]. In the last few decades, the practice of early marriage and early pregnancy were common in Bangladesh despite the substantial development in Human Development Index (HDI) [2]. More than 75 percent of the first-born children were born before women age 20 years and consequently, mortality was 10.4 percent in Bangladesh [3]. It was estimated that more than 50 percent of female adolescents being married before reaching 20 years and thus impacts high maternal, infant and neonatal mortality in

*Address correspondence to this author at the Department of Statistics, University of Rajshahi, Rajshahi- 6205, Bangladesh, Tel: +8801914254013;

E-mail: hossain95@yahoo.com
Bangladesh [4]. The pregnancy rate among adolescents was higher than adult mothers particularly due to their higher fertility rate, poor reproductive knowledge, inexperience and insufficient use of family planning practice and finally inadequate engagement with care providers [5]. ECB mothers need extra attention to consider their health, babies' growth and development during pregnancy and lactation and long term consequences in developing and underdeveloped countries including Bangladesh $[6,7]$. Adolescent mothers with poor health status due to nutritional deficiencies are at higher risk for various diseases [8,9]. The pelvic bone of young mothers may be vulnerable which increases the risk of obstructed labour [10]. The risk of pregnancy-related mortality was double before the age of 15 years than the mother's age 15 to 19 years $[11,12]$. Poverty is the basic cause 
of nutritional deficiency throughout the world. A study on the African-American community in Chicago reported that adolescent mothers were more likely to be unemployed, lived in poverty and be dependent on social welfare [13]. The cultural, religious, economic and other social factors (i.e. education) also impacts early pregnancy and nutritional deficiency; even some community create pressure to probe fertility on a stillgrowing body [14-17]. Other studies established that socio-economic factors such as education, wealth index, age at marriage, number of ever-born children, residence, religion, occupation, place and type of delivery are linked to poor health and nutritional status [18-21].

The Government of Bangladesh (GOB) achieved some health-related millennium development goals (MDGs) such as reducing child mortality and improving maternal health. Now, GOB focuses on Sustainable Development Goals (SDGs) to achieve integrated targets by 2030 [22]. In spite of considerable progress, Bangladesh is still facing trouble with malnutrition that adversely affecting the children and their mother's health.

One study found that the mean age of marriage for Bangladeshi women was $15.69 \pm 2.97$ years which increased the risk of being early mothers [24]. Studies reported that the prevalence of underweight $(\mathrm{BMI}<18.5$ $\mathrm{kg} / \mathrm{m}^{2}$ ) was higher among poor families in both rural $(38.8 \%)$ and urban $(29.7 \%)$ areas [24, 25].

Recently, one study was done on early childbearing among Bangladeshi mothers using the BDHS-2011 dataset. Authors considered only early childbearing mothers and did not compare with non-early childbearing mothers to find the effect of socioeconomic and demographic factors on nutritional status [1]. It is needed to identify the risk factors of early childbearing and its effect on their nutritional status and then comparing it with non-early childbearing mothers using nationally representative last dataset.

Therefore, the aim of the present study was to determine the factors influencing ECB, in addition, we also looked at the effect of ECB on nutritional status among mothers in Bangladesh.

\section{Research Questions}

There are three research questions in this study; these are (i) what is the prevalence of ECB mothers in Bangladesh? (ii) what factors are related to ECB in
Bangladesh? (iii) what is the effect of ECB on nutritional status among mothers in Bangladesh?

\section{METHODS}

A total number of 15,015 non-pregnant Bangladeshi women aged 15-49 years who had at least one ever born child were recruited for the present study from Bangladesh Demographic and Health Survey 2014 from March 24, 2014, to August 11, 2014. BDHS collected different characteristics from 17,863 Bangladeshi married women ages ranged from 15 to 49 years. This is a nationally representative survey that covered all administrative divisions of Bangladesh [22].

\section{Sampling}

BDHS-2014 utilized two stages of stratified cluster sampling for selecting a sample from Bangladeshi married women aged 15-49 years. With this design, the survey selected 18,000 residential households, which were expected to result in completed interviews with about 18,000 ever-married women. Data from a sample of 17,863 married Bangladeshi women were collected. Outliers and missing values and currently pregnant women were excluded from the data. Finally, we analyzed 15,015 data after excluding outliers and missing values and currently pregnant women.

\section{Outcome Variable}

Age at childbearing of mothers was considered as the first outcome variable in this study, and it was classified into two classes as (i) early childbearing (ECB) (delivery first baby before age 20; code $=1$ ), (ii) non-early childbearing (non-ECB) (delivery first baby after age 20; code $=0$ ) mothers. Nutritional status was the second outcome variable of this study which was measured by body mass index (BMI). BMI was categorized into three categories on the basis of cut-off points; (i) undernutrition $\left(\mathrm{BMl}<18.5 \mathrm{~kg} / \mathrm{m}^{2}\right)$ (code, 1) (ii) healthy (normal weight) $\left(18.5 \leq \mathrm{BMl}<25 \mathrm{~kg} / \mathrm{m}^{2}\right)$ (code, 2) and (iii) over nutrition $\left(B M I \geq 25 \mathrm{~kg} / \mathrm{m}^{2}\right.$ ) (code, 3) [26].

\section{Independent Variables}

Various socio-economic and demographic factors were used as independent variables such as divisions (living location), place of residence, parents' education level, number of family members, household wealth index, total ever born children and age at first marriage. All selected independent variables with their categories and codes are described in Table 1. 
Table 1: Independent Variables with their Categories and Codes

\begin{tabular}{|c|c|c|c|c|c|}
\hline Variable & Categories & Code No & Variable & Categories & Code No \\
\hline \multirow{7}{*}{$\begin{array}{l}\text { Division (living } \\
\text { location) }\end{array}$} & Barisal & 1 & \multirow{2}{*}{ Place of residence } & Urban & 1 \\
\hline & Chittagong & 2 & & Rural & 2 \\
\hline & Dhaka & 3 & \multirow{2}{*}{ Age at first marriage } & $<18$ years & 1 \\
\hline & Khulna & 4 & & $18 \geq$ years & 2 \\
\hline & Rajshahi & 5 & \multirow{3}{*}{ Household wealth index } & Poor & 1 \\
\hline & Rangpur & 6 & & Middle & 2 \\
\hline & Sylhet & 7 & & Rich & 3 \\
\hline \multirow{4}{*}{$\begin{array}{c}\text { Respondents' } \\
\text { educational level }\end{array}$} & No education & 0 & \multirow{4}{*}{ Husbands' education level } & No education & 0 \\
\hline & Primary & 1 & & Primary & 1 \\
\hline & Secondary & 2 & & Secondary & 2 \\
\hline & Higher & 3 & & Higher & 3 \\
\hline \multirow{3}{*}{$\begin{array}{l}\text { Total ever born } \\
\text { children }\end{array}$} & $\leq 2$ children & 1 & \multirow{3}{*}{ Number of family member } & $\leq 4$ member & 1 \\
\hline & 3-4 children & 2 & & 5-7 member & 2 \\
\hline & $\geq 5$ children & 3 & & $\geq 8$ member & 3 \\
\hline
\end{tabular}

\section{Statistical Analysis}

Frequency distribution was used to determine the prevalence of early childbearing mothers in Bangladesh. Z-proportion test was used to find the difference in each category of nutritional status between ECB and non-ECB mothers. The Chi-square test was used for selecting independent factors for multilevel logistic regression models. In our dataset the observations came from several levels of hierarchy, it was possible to obtain a clustering effect in the outcome variable. If we are having a clustering effect, we first need to remove it otherwise we could not get actual results, and could not apply a single-level statistical model for analyzing this type of data set [26]. Two levels of multiple logistic regression analysis were used to remove the clustering effect for getting the effect of socio-economic and demographic factors on ECB mothers in Bangladesh.

The two levels models used in the study were:

Level I: $\eta_{i j}=\beta_{0 j}+\beta_{1 j} x_{i j}, P_{i j}=\exp \left(\eta_{i j}\right) / 1+\exp \left(\eta_{i j}\right)$, where $y_{i j}=1$, with probability $P_{i j}$,

$y_{i j}=0$, with probability 1- $P_{i j}, 1 n\left(P_{i j} / 1-P_{i j}\right)=\beta_{0 j}+\beta_{1 j} x_{i j}$

Level II: $\beta_{0 j}=y_{00}+u_{0 j}, \beta_{1 j}=y_{10}, u_{0 j} \sim N\left(0, T_{00}\right), \pi=P(Y$ $\left.=1 \mid X_{1}=x_{1} ; X_{2}=x_{2} ; \ldots ; X_{p}=x_{p}\right)=e^{g}\left(x_{i}\right) / 1+e^{g}\left(x_{i}\right)$, where, $g\left(x_{1}\right)=\beta_{0}+\beta_{1} x_{i 1}+\beta_{2} x_{i 2}+\ldots+\beta_{k} x_{i k} ;(i=1,2, \ldots$, $\mathrm{n})$.

$\beta_{i}=$ unknown logistic regression coefficients $(i=1$, $2, \ldots, n)$.
To check the existence of the clustering effect in the outcome variable, we used the median odds ratio (MOR). The following formula is used for calculating MOR value: $\quad$ MOR $=M O R=\exp \left\{0.6745 \sqrt{2} \sqrt{\sigma_{u}^{2}}\right\}$ $=\exp \left(0.95 \sqrt{\sigma_{u}^{2}}\right)$, where $\sigma_{u}^{2}$ is the cluster variance. There is no evidence of clustering effect if $M O R=1$, but if $M O R>1$, there is cluster variation of outcome variable [28]. We obtained from our dataset, the MOR $=1.372142>1$, there was a clustering effect of the outcome variable (ECB mothers). We selected a twolevel binary logistic regression model for analyzing our data. Level I and II were considered for individual and clusters (EAs) levels respectively. In this study, the magnitude of the standard error (SE) was used to detect the multicollinearity problem, if the magnitude of the SE is less than 0.5 , it was judged that there was no evidence of multicollinearity [28]. The goodness of fit of the model was checked by Hosmer and Lemeshow test. Finally, multinomial logistic regression was used to find the effect of early childbearing on the nutritional status of Bangladeshi mothers. For statistical analysis of data, sampling weight was necessary but unfortunately, proportional allocation technique was not used for selecting samples by BDHS-2014. Sampling weights were calculated for univariate, bivariate and multivariate analysis for this study. Statistical significance was accepted at $p<0.05$. All statistical analyses were performed using SPSS, IBM (version 23.0) and STATA (version 11).

\section{RESULTS}

Out of 15,015 mothers, $83 \%$ were early at the childbearing (ECB) stage. The highest number of early 
childbearing (ECB) mothers $(86.0 \%)$ was living in the Rangpur division while the lowest number of ECB mothers $(77.3 \%)$ was in the Sylhet division. A higher number of ECB mothers (86.1\%) were living in rural areas than urban $(76.9 \%)$. It was found that $41.8 \%$ of ECB mothers had higher education while $87.3 \%$ and $89.2 \%$ had no and primary education respectively. $57.6 \%$ higher educated husbands' wives were ECB, while $88.4 \%$ and $89.7 \%$ no and primary educated husbands' wives were ECB respectively. Also, the percentages of ECB mothers were decreasing with increasing their household wealth quintile. ECB mothers married earlier (aged $<18$ years) than their counterparts. The number and percentages of ECB mothers were increasing with increasing their number of ever born children. Whereas more number (percentage) of ECB mothers $(83.75 \%)$ lived in a large family (member $\geq 5$ ). The Chi-square test demonstrated that all selected variables showed significantly associated with ECB mothers in Bangladesh (Table 2).

The magnitude value of SE for every independent variable in a multivariable two-level logistic model was less than 0.50, there was no evidence of multicollinearity problems among independent variables. After removing the clustering effect of childbearing age, and controlling the effect of other factors on ECB, the two-level model demonstrated that

Table 2: Association between Early Childbearing (ECB) and Household and other Characteristics of Mothers in Bangladesh

\begin{tabular}{|c|c|c|c|c|}
\hline Characteristics & Categories & ECB mothers, $\mathrm{N}(\%)$ & $x^{2}-$ value & p-value \\
\hline \multirow{7}{*}{ Division (living location) } & Barisal & $1502(83.7)$ & \multirow{7}{*}{70.31} & \multirow{7}{*}{$p<0.01$} \\
\hline & Chittagong & $2022(83.9)$ & & \\
\hline & Dhaka & $2084(80.7)$ & & \\
\hline & Khulna & $1836(84.4)$ & & \\
\hline & Rajshahi & $1812(84.2)$ & & \\
\hline & Rangpur & $1864(86.0)$ & & \\
\hline & Sylhet & $1342(77.3)$ & & \\
\hline \multirow{2}{*}{ Place of residence } & Urban & $3882(76.9)$ & \multirow{2}{*}{203.40} & \multirow{2}{*}{$p<0.01$} \\
\hline & Rural & $8580(86.1)$ & & \\
\hline \multirow{4}{*}{ Respondents' educational level } & No education & $3108(87.3)$ & \multirow{7}{*}{1724.35} & \multirow{7}{*}{$p<0.01$} \\
\hline & Primary & $4058(89.2)$ & & \\
\hline & Secondary & $4758(84.7)$ & & \\
\hline & Higher & $538(41.8)$ & & \\
\hline \multirow{3}{*}{ Household wealth index } & Poor & $5010(88.9)$ & & \\
\hline & Middle & $2675(87.5)$ & & \\
\hline & Rich & $4777(75.6)$ & & \\
\hline \multirow{2}{*}{ Age at first marriage } & $<18$ years & $10893(93.4)$ & \multirow{2}{*}{3990.98} & \multirow{2}{*}{$p<0.01$} \\
\hline & $18 \geq$ years & $1569(88.4)$ & & \\
\hline \multirow{4}{*}{ Husbands' educational level } & No education & $3842(88.4)$ & \multirow{4}{*}{1204.04} & \multirow{4}{*}{$p<0.01$} \\
\hline & Primary & $3796(89.7)$ & & \\
\hline & Secondary & 3595 (83.6) & & \\
\hline & Higher & $1229(57.6)$ & & \\
\hline \multirow{3}{*}{ Total ever born children } & $\leq 2$ children & $6346(77.8)$ & \multirow{3}{*}{348.12} & \multirow{3}{*}{$p<0.01$} \\
\hline & 3-4 children & $4300(88.3)$ & & \\
\hline & $\geq 5$ children & $1816(91.3)$ & & \\
\hline \multirow{3}{*}{ Number of family member } & $\leq 4$ member & $5102(81.5)$ & \multirow{3}{*}{18.73} & \multirow{3}{*}{$p<0.01$} \\
\hline & 5-7 member & $5478(84.4)$ & & \\
\hline & $\geq 8$ member & $1882(83.1)$ & & \\
\hline
\end{tabular}


Table 3: Effects of Demographic and Socioeconomic Factors on Early Childbearing among Mothers in Bangladesh

\begin{tabular}{|c|c|c|c|c|c|}
\hline Variable & SE & p-value & AOR & \multicolumn{2}{|c|}{$95 \% \mathrm{Cl}$ of $\mathrm{AOR}$} \\
\hline \multicolumn{6}{|l|}{ Division (living location) } \\
\hline Chittagong Vs Sylhet $^{R}$ & 0.17 & 0.001 & 1.56 & 1.26 & 1.95 \\
\hline Dhaka Vs Sylhet $^{R}$ & 0.14 & 0.040 & 1.25 & 1.00 & 1.54 \\
\hline Khulna Vs Sylhet $^{R}$ & 0.14 & 0.130 & 1.20 & 0.95 & 1.51 \\
\hline Rangpur Vs Sylhet $^{R}$ & 0.17 & 0.005 & 1.40 & 1.10 & 1.77 \\
\hline Barisal Vs Sylhet $^{\mathrm{R}}$ & 0.15 & 0.153 & 1.19 & 0.94 & 1.52 \\
\hline \multicolumn{6}{|l|}{ Place of residence } \\
\hline Rural Vs Urban ${ }^{R}$ & 0.07 & 0.280 & 1.08 & 0.94 & 1.23 \\
\hline Primary Vs Higher ${ }^{R}$ & 0.22 & 0.001 & 2.36 & 1.97 & 2.82 \\
\hline Secondary Vs Higher ${ }^{R}$ & 0.21 & 0.001 & 1.99 & 1.60 & 2.48 \\
\hline \multicolumn{6}{|l|}{ Household wealth index } \\
\hline Middle Vs Poor ${ }^{R}$ & 0.09 & 0.580 & 1.05 & 0.89 & 1.23 \\
\hline Rich Vs Poor ${ }^{R}$ & 0.07 & 0.040 & 0.85 & 0.73 & 0.99 \\
\hline \multicolumn{6}{|l|}{ Age at first marriage (Year) } \\
\hline$<18 V_{s} \geq 18^{R}$ & 0.43 & 0.001 & 12.58 & 11.23 & 14.08 \\
\hline \multicolumn{6}{|l|}{ Husbands' educational level } \\
\hline No education Vs Higher ${ }^{R}$ & 0.21 & 0.001 & 1.95 & 1.57 & 2.41 \\
\hline \multicolumn{6}{|l|}{ Number of family member } \\
\hline 5-7 member $V s \leq 4$ member $^{R}$ & 0.07 & 0.040 & 1.13 & 1.01 & 1.27 \\
\hline$\geq 8$ member $V s \leq 4$ member $^{R}$ & 0.10 & 0.002 & 1.29 & 1.10 & 1.52 \\
\hline Goodness of Fit & \multicolumn{5}{|c|}{ Hosmer and Lemeshow test, $x^{2}$-value $=9.032, p=0.340$} \\
\hline
\end{tabular}

N.B.: B-Coefficients, SE-Standard error, Cl-Confidence interval, AOR-Adjusted odd ratio, R-Reference case.

women living in Chittagong [AOR=1.56, 95\% Cl: $1.26-$ 1.95; $p<0.01$ ], Dhaka [AOR=1.25, $95 \% \mathrm{Cl}: 1.00-1.54$; $\mathrm{p}<0.05]$ and Rangpur $[\mathrm{AOR}=1.40,95 \% \mathrm{Cl}: 1.10-1.77$; $\mathrm{p}<0.01$ ] divisions were $1.56,1.25$ and 1.40 times greater risk to become ECB mothers than women living in Sylhet division respectively. Uneducated $[A O R=1.28$, 95\% Cl: $1.01-1.64 ; p<0.05]$, primary [AOR $=2.36,95 \%$ Cl: $1.97-2.82 ; p<0.01]$ and secondary $[A O R=1.99,95 \%$ Cl: $1.60-2.48 ; p<0.01]$ educated women were more likely to become ECB mothers compared to higher educated mothers. Women living in the poor family is
$15 \%$ more likely to become ECB mothers compared to women living in a rich family [AOR $=0.85,95 \% \mathrm{Cl}$ : $0.73-$ $0.99 ; \mathrm{p}<0.05]$. It was found that women who got married earlier (age $<18$ years) had a 12.58-fold greater risk to become ECB mothers than their counterparts [AOR=12.58, 95\% Cl: $11.23-14.08 ; \quad \mathrm{p}<0.01]$. Uneducated [AOR=1.95, 95\% Cl: 1.57-2.41; $\mathrm{p}<0.01$ ], primary $[A O R=2.52,95 \% \mathrm{Cl}: 2.07-3.06 ; \mathrm{p}<0.01]$ and secondary [AOR $=1.80,95 \% \mathrm{Cl}: 1.52-2.12 ; \mathrm{p}<0.01]$ educated husbands' wives had respectively 1.95, 2.52 and 1.80 times greater risk to become ECB mothers 
Table 4: The Prevalence of Nutritional Status among Early and Non-Early Childbearing Mothers in Bangladesh

\begin{tabular}{|c|c|c|c|c|}
\hline Nutritional status, $\mathrm{N}(\%)$ & ECB mothers, $\mathrm{N}(\%)$ & Non- ECB mothers, $\mathrm{N}(\%)$ & Z-value & p-value \\
\hline Under nutrition, 2643(17.6) & $2301(18.5)$ & $342(13.4)$ & 2.2986 & 0.0214 \\
\hline Normal (healthy), 8543(56.9) & $7198(57.8)$ & $1345(52.7)$ & 3.4678 & $p<0.01$ \\
\hline Over nutrition, 3829(25.5) & $2963(23.7)$ & $866(33.9)$ & -6.0192 & $p<0.01$ \\
\hline Total & 12462 & 2553 & & \\
\hline
\end{tabular}

N.B.: ECB: Early childbearing.

Table 5: Effect of Early Childbearing on Nutritional Status of Mothers in Bangladesh

\begin{tabular}{|c|c|c|c|c|c|c|c|c|}
\hline \multirow[t]{2}{*}{ Nutritional status } & \multirow[t]{2}{*}{ COR } & \multicolumn{2}{|c|}{ COR $(95 \% \mathrm{Cl})$} & \multirow[t]{2}{*}{ p-value } & \multirow[t]{2}{*}{$\mathrm{AOR}^{\neq \neq}$} & \multicolumn{2}{|c|}{ AOR $(95 \% \mathrm{CI})$} & \multirow[t]{2}{*}{ p-value } \\
\hline & & Lower & Upper & & & Lower & Upper & \\
\hline $\begin{array}{l}\text { Under nutrition } \\
\text { Vs Normal }\end{array}$ & 1.26 & 1.11 & 1.43 & $p<0.01$ & 1.21 & 0.96 & 1.30 & 0.14 \\
\hline $\begin{array}{l}\text { Over nutrition } \\
\text { Vs Normal }\end{array}$ & 0.64 & 0.58 & 0.70 & $p<0.01$ & 0.88 & 0.78 & 0.99 & 0.04 \\
\hline
\end{tabular}

N.B.: B-Coefficient; COR-Crude odds ratio; Cl-Confidence interval; AOR-Adjusted odds ratio; R-Reference.

${ }^{\# \neq}$ Adjusted of other all selected independent factors.

compared to higher educated husbands' wives. It was observed that the AOR was increasing with increasing the number of children; early childbearing mothers had comparatively more ever born children than their counterparts. Women living in a family having $5-7$ $[A O R=1.13,95 \% \quad \mathrm{Cl}: 1.01-1.27 ; p<0.01]$ and $\geq 8$ [AOR=1.29, 95\% Cl: 1.10-1.52; $p<0.01]$ members had a 1.13 and 1.29-fold higher risk to become ECB mothers than women living in the comparatively small family ( $\leq 4$ members). Hosmer and Lemeshow test (Chi-square value $=9.032, p=0.340$ ) showed that our selected model was well fitted to our data (Table 3 ).

The nutritional status among ECB and non- ECB mothers in Bangladesh is presented in Table 4. It was noted that $25.5 \%$ of mothers in Bangladesh were overnourished, while $17.6 \%$ of mothers were undernourished. Z-proportional test demonstrated that significantly a greater number of ECB mothers (18.5\%) were undernourished than that of non- ECB mothers $(13.4 \%)(p<0.05)$, while the number of overnourished mothers among non- ECB (33.9\%) was significantly higher than ECB mothers $(23.7 \%)(p<0.01)$. Also, it was observed that the number of healthy among $\mathrm{ECB}$ mothers $(57.8 \%)$ was higher than that of non-ECB mothers $(52.7 \%)(p<0.01)$ (Table 4$)$.

Nutritional status was three categories; (i) undernutrition, (ii) healthy and (iii) over nutrition. It was used as a dependent variable; multinomial logistic regression was used to find the effect of ECB on nutritional status. Healthy mothers were considered as reference cases. Both univariable and multivariable multinomial logistic models were used for this purpose. The univariable model demonstrated that ECB mothers had a 1.26-fold greater risk to be undernourished than non-ECB mothers [COR=1.26, 95\% Cl: 1.11-1.43; $p<0.01]$. It was also found that ECB mothers had a $36 \%$ higher chance to get normal weight compared to non-ECB mothers [COR=0.64, 95\% Cl: 0.58-0.70; $p<0.01]$. The multivariable model showed that ECB mothers were more likely to get normal weight by $12 \%$ than non-ECB mothers $[A O R=0.88,95 \% \mathrm{Cl}: 0.78-0.99$; $p<0.05$ ] (Table 5).

\section{DISCUSSION}

Globally around 17 million adolescent girls give birth each year comprising $11.0 \%$ of all births and $90 \%$ of them occurs in low and middle-income countries. The most prevalent countries are Bangladesh, Brazil, the Democratic Republic of the Congo, Ethiopia, India, Nigeria and the United States [29]. Early pregnancy and motherhood are still common in Bangladesh. This study investigated the factors which influence ECB among Bangladeshi mothers because ECB creates a poor nutritional status of mothers. Some studies in Bangladesh found the effects of various factors on the nutritional status of ECB mothers in Bangladesh using BDHS 2007 and 2011 data [1, 2]. Moreover, they did not compare with non-ECB mothers. In the present study, we investigated the factors influencing ECB among Bangladeshi mothers, using Bangladesh 
Demographic Health Survey data 2014 (BDHS 2014) which was the latest dataset. However, our findings showed that the overall prevalence of ECB among Bangladeshi mothers was $83 \%$ which were slightly lower than the previous study (86\%) from BDHS 2011 [1]. The percentage of ECB among mothers has decreased due to the increase in the female education and household wealth quintile during the last two decades in Bangladesh and these may be the most important reason for the development of ECB [23].

\section{Effect of Socio-Economic and Demographic Factors on ECB}

We analyzed the divisional distribution of ECB as regional coverage. The prevalence of ECB mothers was varied among divisions' and the highest number of ECB was observed in Rangpur and lowest in Sylhet division due to differentiation of customs, cultures and economic conditions among the regions [30-32]. Therefore, these facts could be potential reasons for ECB. A study in Brazil found a strong association between childbearing at young ages and the mother's subsequent economic and social indicators. Young mothers were less likely to complete high school, less likely to participate in the labour force, more likely to have lower earnings, than women who did not bear children as teenagers [33]. The effect of education may be explained by the likelihood that educated mothers are more able to receive and understand health promotion messages. This study also exhibited that a positive association exist between a mother's education level and ECB. The illiterate are more likely to be ECB than educated mothers. Subsequently, the higher educated mothers were 0.797 times less likely to be ECB than uneducated mothers. This could be depicted as the fact that uneducated mothers were mostly served as housewives with improper knowledge of the effect of early pregnancy. Our results revealed that mothers from rural areas were more likely to commence early pregnancy than urban areas. Similar results were observed among other south Asian mothers in India and Nepal [8, 34]. The other necessary socio-economic characteristics were also considered in this study such as the number of the family members, total ever born children, age at first marriage and household wealth quintile [1].

\section{Impact of ECB on Nutritional Status}

In this study, we found that Bangladeshi mothers had faced the dual burden of malnutrition; still, more than $17 \%$ of mothers were suffering from chronic energy deficiency while $25 \%$ of mothers were overnourished. The trends in the number of overnourished mothers in Bangladesh have been increasing but the number of undernourished mothers has been decreasing with increasing the household wealth quintile during the last two decades in Bangladesh [23]. The prevalence of undernutrition among ECB mothers was significantly higher than that of non- ECB mothers. This may indicate the impact of ECB with other mentioned contributing factors. Interestingly, the prevalence of healthy among ECB mothers was also significantly higher than their counterparts may illustrate the optimum utilization of nutrients by young mothers. Alternatively, the prevalence of overnutrition was lower among ECB mothers than non- ECB mothers. This also indicates the imbalance of intake and utilization of nutrients by adult mothers. These results were also supported by the previous study based on Bangladesh Demographic and Health Survey, 2011 [1] and also a cross-sectional study among the nutritional and health risks among adolescent pregnant mothers in Bangladesh [35].

\section{Strength and Limitation of the Study}

Perhaps, it is the first time to investigate the associated factors of ECB mothers in Bangladesh and analyze the effect of ECB on their nutritional status compared with non-ECB mothers. We analyzed also the risk factors were identified after removing the clustering effect of ECB using multilevel binary logistic regression analysis. However, there were some limitations of this study. We used secondary crosssectional data derived from BDHS-2014, women's parental related factors were not available such as the household wealth quintile of women's parents before their marriage, the education level of parents which were more important predictors for early marriage as well as ECB. Sampling weight was essential to analyze BDHS-2014 data for ensuring national representation of the survey, but in this survey, we did not consider a proportional allocation technique for selecting samples from different regions such as divisions. We only controlled the effect of some socio-economic, demographic and anthropometric factors for determining the effect of ECB mothers on their nutritional status, but physiological factors which may also impact nutritional status such as level of physical activities, level of energy intake and behavior patterns like dietary habits, smoking habits, weight maintenance, methods of weight-loss etc $[36,37]$ due to unavailability of these factors in BDHS-2014 dataset. However, the mentioned factors would be the potential 
clues for researchers to conduct more research on ECB mothers in Bangladesh.

\section{CONCLUSIONS}

We investigated the factors of ECB among nonpregnant mothers in Bangladesh aged 15-49 years and compared with non-ECB non-pregnant mothers, in addition, the effect of ECB on nutritional status were also observed. Two-level and multinomial logistic regression models were applied to find the effect of socio-economic and demographic factors on ECB and the effect of ECB on nutritional status of mothers respectively. The prevalence of ECB mothers in Bangladesh was $83 \%$. It was found that living location (division), respondents and their husbands' education, household wealth quintile, age at first marriage, number of family members were the predictors of ECB among mothers in Bangladesh. Still, $17.6 \%$ of mothers were suffering from chronic energy deficiency; among them, $18.5 \%$ and $13.4 \%$ were ECB and non- ECB mothers respectively. On the other hand, $25.5 \%$ of mothers in Bangladesh were overnourished, among them $23.7 \%$ and $33.9 \%$ were ECB and non- ECB mothers respectively. ECB mothers had a higher risk to be underweight than non-ECB mothers. The health authorities of the Bangladesh government and nongovernment organizations should special attention to childbearing mothers' health and nutritional status due to their potential contribution to the family and productivity. We hope our findings could be considered to reduce the ECB mothers in Bangladesh as well as to improve their nutritional status.

\section{LIST OF ABBREVIATIONS}

\begin{tabular}{|c|c|c|}
\hline AOR & $=$ Adjusted odd ratio & \\
\hline BBS & $=$ Bangladesh Bureau of Statistics & \\
\hline BDHS & 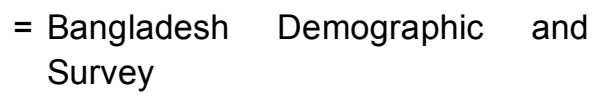 & Health \\
\hline BMI & $=$ Body mass index & \\
\hline $\mathrm{Cl}$ & $=$ Confidence interval & \\
\hline COR & $=$ Crude odds ratio & \\
\hline EAs & $=$ Enumeration areas & \\
\hline OB & $=$ Government of Bangladesh & \\
\hline HDI & $=$ Human Development Index & \\
\hline
\end{tabular}

IBM = International Business Machines

MDGs = Millennium development goals

MOR = Median odds ratio

PSU = Primary SamplingUunit

SDGs = Sustainable development goals

SE $\quad=$ Standard error

SPSS = Statistical Package For Social Sciences

STATA = Software for Statistics and Data Science

Ups = Union parishads

\section{DECLARATIONS}

\section{Ethics Approval and Consent to Participate}

The 2014 BDHS received ethics approval from the Ministry of Health and Family Welfare, Bangladesh. The 2014 BDHS also received written informed consent for participation in the study was obtained where participants were children (under 16 years old) from their parent or guardian.

\section{Consent for Publication}

Not applicable for this study.

\section{Availability of Data and Material}

The BDHS-2014 datasets are freely available at https://dhsprogram.com/data/dataset/Bangladesh_Stan dard-DHS_2014.cfm?flag $=0$

\section{Competing Interests}

The authors have no conflict of interests.

\section{Funding}

There was no grant, technical or corporate support for this study.

\section{Authors Contributions}

$\mathrm{KS}$ and $\mathrm{MGH}$ conceptualized and designed the research; ASMAM analyzed the data; KS, MAS drafted the original manuscript; MGH, SC, PB, MAT and MAS critically reviewed and edited the manuscript. All the authors read, discussed and approved the final version of the manuscript for publication. 


\section{ACKNOWLEDGEMENTS}

The authors would like to acknowledge Bangladesh Demographic and Health Survey (BDHS) and NIPORT for providing the data collected in 2014.

\section{REFERENCES}

[1] Islam A, Islam N, Bharati P, Aik S, Hossain G. Socioeconomic and demographic factors influencing nutritional status among early childbearing young mothers in Bangladesh. BMC Women's Health 2016; 16: 58. https://doi.org/10.1186/s12905-016-0338-y

[2] Kamal SMM. Adolescent motherhood in Bangladesh: Evidence from 2007 BDHS data. Can Stud in Popul 2012; 39(1-2): 63-82. https://doi.org/10.25336/P6KG7R

[3] Maitra P, Pal S. Early Childbirth, Health Inputs and Child Mortality: Recent Evidence from Bangladesh. IZA Discussion Paper Series, No. 2841 2007; Bonn: Germany.

[4] NIPORT. National Institute of Population Research and Training, Bangladesh demographic and health survey Dhaka, Mitra \& Associates and Macro International, Bangladesh and Maryland, USA, 2009.

[5] Islam MM, Islam M.K, Hasan MS, Hossain MB. Adolescent motherhood in Bangladesh: Trends and determinants. PLoS ONE 2017; 12(11): e0188294. https://doi.org/10.1371/journal.pone.0188294

[6] Kominiarek MA, Rajan P. Nutrition Recommendations in Pregnancy and Lactation. Med Clin North Am 2016; 100(6): 1199-1215. https://doi.org/10.1016/j.mcna.2016.06.004

[7] Goli S, Rammohan A, Singh D. The Effect of Early Marriages and Early Childbearing on Women's Nutritional Status in India. Matern Child Health J 2015; 19(8): 1864-80. https://doi.org/10.1007/s10995-015-1700-7

[8] Palacios J, Kennedy HP. Reflections of Native American teen mothers. J Obstet Gynecol Neonatal Nurs 2011; 39(4): 425-34.

https://doi.org/10.1111/j.1552-6909.2010.01149.x

[9] Sayem MA, Matin MN, Islam MS, Matubbar MS, Alam MM. The Morbidity Outcomes of Teenage Pregnancy at rural Netrakona in Bangladesh. Int. J Percept. Public Health 2018; 2(3): 165-177.

https://doi.org/10.29251/ijpph.201877

[10] Nour NM. Health Consequences of Child Marriage in Africa. Emerg Infect Dis 2006; 12(11): 1644-9. https://doi.org/10.3201/eid1211.060510

[11] United Nations. We the children: end-decade review of the follow-up to the World Summit for Children. Report of the Secretary-General (A/S-27/3). New York: United Nations; 2001.

[12] UNESCO. Case Studies. Malaysia Demographic Charact eristic of Adolescents. Adolescent Health Reprodu ctive and Sexual Health Bangkok: UNESCO; 2004.

[13] Assini-Meytin LC, Kerry MS, Green M. Long-Term Consequences of Adolescent Parenthood Among AfricanAmerican Urban Youth: A Propensity Score Matching Approach. J Adolesc Health 2015; 56(5): 529-35. https://doi.org/10.1016/.j.jadohealth.2015.01.005

[14] Scholl TO, Hediger ML, Salmon RW, Belsky DH, Ances IG. Association between Gynecological Age and Preterm Birth. Pediatric and Perinatal Epidemiology 1989; 3: 357-366. https://doi.org/10.1111/j.1365-3016.1989.tb00524.x

[15] Paranjothy S, Broughton H, Adappa R, Fone D. Teenage Pregnancy: Who Suffers? Archives of Disease in Childhood 2008; 94, 239-245.

https://doi.org/10.1136/adc.2007.115915
[16]

Bacci A, Manhica GM, Machungo F, Bugalho A, Cuttini M. Outcome of Teenage Pregnancy in Maputo, Mozambique. International Journal of Gynaecology \& Obstetrics 1993; 40 19-23.

https://doi.org/10.1016/0020-7292(93)90767-Q

[17] Chen $X$, Wen SW, Fleming $N$. Teenage pregnancy and adverse birth outcomes: A large population based retrospective cohort study. International Journal of Epidemiology 2007; 36: 368-373. https://doi.org/10.1093/ije/dyl284

[18] Khan MM, Krämer A, Khandoker A, Prüfer-Krämer L, Islam A. Trends in socio-demographic and health-related indicators in Bangladesh 1993-2007: will inequities persist?" Bull World Health Organ 2011; 89: 583-93. https://doi.org/10.2471/BLT.11.087429

[19] Hossain MG, Bharati P, Aik S, Lestrel PE, Abeer A, Kamarul $\mathrm{T}$. Body mass index of married Bangladeshi women: trends and association with socio-demographic factors. J Biosoc Sci 2012; 44(4): 385-99. https://doi.org/10.1017/S002193201200003X

[20] Subramanian SV, Perkins JM, Khan KT. Do burdens of underweight and overweight coexist among lower socioeconomic groups in India? Am J Clin Nutr 2009; 90(2): 369-76.

https://doi.org/10.3945/ajen.2009.27487

[21] Bharati S, Pal M, Bhattacharya BN, Bharati P. Prevalence and causes of chronic energy deficiency and obesity in Indian women. Hum Biol 2007; 79(4): 395-412. https://doi.org/10.1353/hub.2007.0048

[22] NIPORT. Bangladesh Demographic and Health Survey 2014 National Institute of Population Research and Training, Dhaka; Mitra \& Associates and ORC Marco, Bangladesh and Calvertion, MD,USA 2014

[23] Gnudi S, Sitta E, Lisi L. Relationship of body mass index with main limb fragility fractures in postmenopausal women. $J$ Bone Miner Res 2009; 27(4): 479-84. https://doi.org/10.1007/s00774-009-0056-8

[24] Hossain MG, Mahumud RA, Aik S. Prevalence of child marriage among Bangladeshi women and trend of change over time. J Biosoc Sci 2016; 48 (4): 530-8. https://doi.org/10.1017/S0021932015000279

[25] World Health Organization. Diet, Nutrition and the prevention of Chronic diseases, vol. 916. Geneva: Report of a Joint WHO/FAO Expert Consultation; 2003.

[26] Khan MHR, Shaw JEH. Multilevel logistic regression analysis applied to binary contraceptive prevalence data. J Data Sci 2011; 9: 93-110.

[27] Larsen K, Merlo J. Appropriate assessment of neighborhood effects on individual health: integrating random and fixed effects in multilevel logistic regression. Am J Epidemiol 2005; 161(1): 81-8. https://doi.org/10.1093/aje/kwi017

[28] Chan YH. Biostatistics 202: logistic regression analysis Singapore Med J 2004; 45(4): 149-153.

[29] World Health Organization. Adolescent pregnancy: WHO factsheet 2014 2017. Available at : http: //www who.int/mediacentre/ factsheets/ fs 364/en/.

[30] Geronimus AT. Teenage childbearing as cultural prism British Medical Bulletin 2004; 69: 155-166. https://doi.org/10.1093/bmb/ldh019

[31] Kramer KL, Lancaster JB. Teen motherhood in cross-cultural perspective. Annals of Human Biology 2010; 37(5): 613-628. https://doi.org/10.3109/03014460903563434

[32] Hoffman SD. Teen Childbearing and Economics: A Short History of a 25-Year Research Love Affair. Societies 2015; 5 : 646-663.

https://doi.org/10.3390/soc5030646 
[33] Narita R, Diaz MDM. Teenage motherhood, education, and labor market outcomes of the mother: Evidence from Brazilian data. Economi A 2016; 17: 238-252. https://doi.org/10.1016/j.econ.2016.05.003

[34] Choe MK, Thapa S, Achmad S. Early marriage and childbearing in Indonesia and Nepal. East-West Center Working Papers, Population Series 2001: 108-115.

[35] Nguyen PH, Sanghvi T, Tran LM, Afsana K, Mahmud Z, Aktar B, et al. The nutrition and health risks faced by pregnant adolescents: Insights from a cross-sectional study in Bangladesh. PLoS ONE 2017; 12(6): e0178878. https://doi.org/10.1371/journal.pone.0178878
[36] Najat Y, Alice A, Abbass A, Rizk S. Eating habits and obesity among Lebanese university students. Nutr J 2008; 7: 32. https://doi.org/10.1186/1475-2891-7-32

[37] Cilliers J, Senekal M, Kunneke E. The association between the body mass index of First year female university students and their weight-related perceptions and practices, psychological health, physical activity and other physical health indicators. Public HealthNutr 2006; 9(2): 234-43. https://doi.org/10.1079/PHN2005846

Received on 07-08-2021

https://doi.org/10.6000/1929-6029.2021.10.09

(C) 2021 Sumon et al.; Licensee Lifescience Global.

This is an open access article licensed under the terms of the Creative Commons Attribution License (http://creativecommons.org/licenses/by/4.0/) which permits unrestricted use, distribution and reproduction in any medium, provided the work is properly cited. 